\title{
Reflection on teaching effective social work practice for working with Muslim communities
}

\author{
Khadija Khaja \\ Chelsea Frederick
}

\begin{abstract}
In many academic departments like social work, psychology, and psychiatry there is a growing consensus that teachers need to instruct students to be culturally competent especially if they are going to be effective helpers with diverse populations. Multicultural instructional counseling methods are imperative if we are to ensure that our students of counseling are well prepared to work with diverse families, particularly those from Muslim backgrounds. In this narrative the author writes about the challenges of teaching non-Muslim students effective counseling techniques with Muslim families. Culturally innovative teaching methods are illustrated to facilitate students' learning how to be effective counselors with Muslim communities.
\end{abstract}

Keywords: Muslims, Islam, Spirituality, Religion, Clinical Skills, Counseling

\section{INTRODUCTION}

It is never easy to teach students how to be effective social workers. Those of us that have years of experience teaching social work in the West whether it be in colleges or universities realize that each individual, family, or group is different, and will require different types of interventions. In many academic departments like social work, psychology, and psychiatry there is a growing consensus that teachers need to instruct students to be culturally competent especially if they are going to be effective helpers with diverse populations (Brammer, 2004). This is not as easy as it sounds. Western helping frameworks generally appear to stress individual self-sufficiency, independence, and autonomy. The majority of students in the United States learn counseling techniques which were primarily designed to serve European American families (Brammer, 2004). This could explain why many minority groups end counseling faster than European American clients do (Ridley, 1989). The importance of teaching culturally competent social work practice became even more relevant when the horrific attacks took place against the World Trade Center on September 11, 2001. Negative images of Muslims were prevalent in the media, which created internalized fear or anger even in the best of social work students (Brammer, 2004). Thus, teaching non-Muslim social work students how to be effective helpers with Muslim families can be a rather daunting and challenging task. Carter and Rashidi (2004) report that most Muslim families who have migrated to the West continue to support their traditional beliefs. Most Western social work students, however, do not even know what this means. This should reinforce that as teachers we should, and can play a leadership role in classrooms by making sure our students understand how best to help Muslims. This paper will illustrate lessons learned

Khadiji Khaja Ph.D is an assistant professor and Chelsea Frederick B.S.W. is a graduate student at Indiana University School of Social Work, Indianapolis.

Copyright (c) 2008 Advances in Social Work Vol. 9 No. 1 (Spring 2008), 1-7. 
in classrooms when trying to educate mainstream non-Muslim students about how to effectively engage in social work practice with Muslim communities.

\section{EDUCATING SOCIAL WORK STUDENTS ABOUT MUSLIMS}

One of the first things a teacher can do is illustrate that understanding and helping Muslims is relevant simply because of the population's growing demographics. This sounds like a fairly simple task, but it is powerful because it grabs the attention of the social work classroom. Today over one billion, or nearly one in five people around the world are Muslim. The Islamic faith is the second largest in the world, and there are at least fifty countries around the world in which Muslims represent the majority of the population (Carter \& Rashidi, 2004). While the continents of Asia and Africa have the largest populations of Muslims, migration patterns have led to many Muslims migrating to North America (Khaja, 2004). Many have migrated due to civil and political conflicts, to have access to better education and economic opportunities for their families, or to escape religious persecution, and civil wars (Carter \& Rashidi, 2004). Seven to eight million Muslims live in the United States (Rashid, 1999). To prevent stereotyping, it is also important to reinforce to students that $80 \%$ of the Muslim world is not Arab, and that 90\% of Arab Americans are Christian (Reizian \& Meleis, 1986). Sharing these demographics in social work classrooms is important because it breaks common misconceptions that can be detrimental to both Muslims and Arabs. Also, when students learn how large the Muslim community is they become interested, curious, intrigued, and committed to their learning. This is because students realize there is a strong possibility that they will eventually have a helping relationship with a Muslim, whether it be in a role as an advocate, case manager, counselor, community development worker, or administrator.

\section{STIGMA OF MENTAL HEALTH}

It is critical to teach students that Muslim clients have to be the ones that educate a social worker on their lives, supports, and resources (Carter \& Rashidi, 2004). It is, however, equally important to educate students that the term "mental health", used commonly in Western social work classrooms, must be used cautiously. Asking anyone to reveal whether they have a mental health concern, or asking them to fill out a form sharing whether they have a mental health diagnosis is never easy, with a Muslim it is even more challenging. This can be met with extreme resistance and anger. This is because mental health issues are still viewed in a shameful manner in many Muslim communities. Often such issues are dealt with privately in the home or with the help of extended family. It is not unusual to hear about cases where Muslims have experienced various mental health issues such as depression, anxiety, and psychosis, but suffered silently or were very apprehensive to reach out for help for fear of community gossip (Khaja, 2004). For example, in Saudi Arabia, and Pakistan, a stigma still exists that mental illness is caused by the affliction of evil spirits (Pridmore \& Pasha, 2004). Muslim mental health patients in such areas are reported to have been chained, burned, beaten, or undergone exorcisms (Pridmore \& Pasha, 2004). Hence, it is important to educate students that it is probably better to ask Muslim clients if they are experiencing any emotional stresses instead of asking if they have any mental health issues or concerns, 
especially if a social worker needs the information for an assessment or intake form. Clearly stressing confidentiality and what mitigating conditions it can be broken under can alleviate some stress for the Muslim client that reaches out to a Western mainstream social work agency. Speaking about medications that treat mental health issues cannot be taken lightly either. It is not unusual to hear Muslim families saying they are against taking medications to cope with mental health issues, as it is considered a sign of spiritual weakness. While there are some Muslims that use medications to deal with mental health issues, more studies are needed that explore how common or accepted this practice is.

\section{TEACHING SPIRITUAL HEALING OF MUSLIMS}

Teaching social work students how to help Muslim clients needs to involve education on the role of spirituality (Carter \& Rashidi, 2004). Islam often guides how Muslim families live (Carter \& Rashidi, 2004). Hence, it is important to educate students on the basic tenants of Islam. For example, the author will often invite a guest speaker from an Islamic Center who will educate students on Islam. Students quickly learn that the average Muslim family follows the Qur'an which is the Holy Scripture of Muslims, and sunnah which are traditions of Prophet Muhummed, both of which often play a central role when families face difficulties (Carter \& Rashidi, 2004). The average Muslim family will consult with experts of the Qur'an, and sunnah when they are dealing with any concerns. Students are often surprised to learn that the Qur'an provides guidance on family and company, ethics and etiquette, economic well being, order, charity, models of family conduct, social welfare, and oppression (Eliyasee \& Picktall, 1996). Experts in the Qur'an are often contacted where they will suggest various healing techniques such as reciting paragraphs of the Qur'an a certain amount of times, use of herbs, and special diets. Thus the role of the Qur'an in counseling Muslim families is quite central, and cannot be underestimated or ignored. Therefore it is important to educate Western counseling students that many Muslims would probably feel more comfortable consulting a well trained Sheik or Moalj Bel-Koran (Muslim Traditional Healer) to help them with emotional struggles instead of relying only on the Western trained counselor (Al-Krenawi \& Graham, 1999). This can lead to more referrals to Muslim traditional healers, and will ensure that Western counseling students appreciate the importance of spirituality in the lives of Muslim families, and that interventions by God are seen as critical to dealing with emotional crises in many Muslim families (Al-Krenawi \& Graham, 1999). A central concept of Islam is the "belief in fate, that all things that happen to a person, both good and evil, are the will of God” (Al-Krenawi \& Graham, p. 55. 1999).

\section{TEACHING MUSLIM PSYCHOTHERAPY}

I also educate my students on the Arabic word Islam which literally means peace, and belief in only one God, Allah (Carter \& Rashidi, 2004). For Muslims, their higher power is Allah (Carter \& Rashidi, 2004). The next step is to educate counseling students on the purpose of helping Muslim families. For example, in western counseling techniques the focus might be on people realizing strengths, coping mechanisms, dealing with past conflicts, and finding solutions. However, in Muslim counseling methods we try to help families in a deeply holistic manner (Carter \& Rashidi, 2004). The focus is on 
balance between mind, and body (Carter \& Rashidi, 2004). Counseling techniques need to therefore focus on peace in the "spirit (Rouh), mind (Aghl), soul (Nafs), intellect (Aghlaniah, Tafakkor), body (Badan or Jesm) and emotion (Atefah)" (Carter \& Rashidi, 2004, p. 153, 2004). The Quran sees all these parts as connected, and if one area is not functioning well, the spiritual balance of mind and body are adversely affected. The concepts of "inner tranquility" and "peace" need to be the central point of counseling (Carter \& Rashidi, 2004, p. 154). A person must have virtue inside, and practice it externally (Carter \& Rashidi, 2004). This is done with a strict diet, fasting, prayer, and meditation. This is believed to lead to a person having balance "physically", “emotionally”, "spiritually”, and "mentally” (Carter \& Rashidi, p. 155).

\section{ROLES OF GENDER IN COUNSELING}

Counselors of a different gender than clients can pose a problem. It is not unusual to hear that a Muslim woman would have difficulty seeking help from a male counselor because she "cannot occupy private space together without the presence of another person” (Carter \& Rashidi, 2004, p. 153). To complicate matters further, both male and female clients cannot look at counselors of the opposite sex directly, a common practice in many Muslim families (Carter \& Rashidi, 2004). Because of this counselors may wrongly assume that the client is "lying" or has poor self-esteem (Carter \& Rashidi, 2004, p.153). Physical contact as simple as a handshake is not permissible in many Islamic cultures. Males may often be expected to enter or leave a room first (Carter \& Rashidi, 2004). The counselor may erroneously assume this is a sign of disrespect when actually the client believes they are showing respect. It would also not be unusual to bring other family members to sessions even if the concern pertained to individual matters. A counselor should also realize that statues or pictures of people in a room can be offensive to Muslims as this was equated to idol worship in early Islamic times. Even the smell of pork or ham can be seen as offensive as Muslims are forbidden to eat flesh from a pig. In many Muslim families, extended family supports are critical, and their expertise or wisdom will be sought even in counseling matters (Carter \& Rashidi, 2004). Patience in times of adversity, and helping others are seen as key ways to deal with trouble in one's inner peace (Carter \& Rashidi, 2004).

\section{HEALING THE MUSLIM HEART}

It is important to teach mainstream social work students that many Muslim believe that healing of one's heart is seen as critical to ensuring a peaceful life without any emotional troubles or conflicts. Purification and cleansing of the soul (tazkiat) is seen as the ultimate form of healing for the Muslim heart (Farid, 1991). Mental health issues can often be seen as resulting from a sick or dead heart (Farid, 1991). Many Muslims believe that a person with a healthy heart does not give in to temptations, has hope, and dedicates life to God (Farid, 1991). It is believed that a person with a sick heart is focused on materialistic things in this world, and will suffer deeply (Farid, 1991). The person with a dead heart is viewed as focusing on "lust", "desire", and "worships things" other than God (Farid, 1991, p.15). This person does not listen to those trying to help, has great impulsivity, can be manipulative, and lives in a world of fantasy (Farid, 1991). 
Those with a sick or dead heart are viewed as people who have a soul that lacks remorse, and are preoccupied with this world (Farid, 1991). Temptations are seen as the main causes of a sick or dead heart.

Four areas are considered particularly poisonous to the Muslim heart. Talking a great deal without praise of God is believed to "harden" the heart (Farid, p. 20, 1991). What we utter, and how we utter it is believed to affect our peace. Farid (1991) states that "those who sow the seeds of good words and deeds harvest honor and blessings; those who sowed the seeds of evil words and deeds reap only regret and remorse” (p. 20). It is also important to educate mainstream social work students that glances of the eye are seen as something that can affect our inner peace in the heart. For example, many Muslims believe the eye and the heart are intrinsically connected. If we enjoy viewing things that hurt other humans our heart decays (Farid, 1991). The heart becomes more preoccupied with the "beautiful" instead of being preoccupied with "worship" (Farid, 1991, p. 23). This is one of the main reasons why Muslims are expected to lower their gaze when interacting with others so that the temptations of the devil do not pass through (Farid, 1991). If the heart is "dark" problems will overcome the individual. If the heart "lights up" positives things will happen to the individual (Farid, 1991).

Diet is considered intrinsic to a healthy inner peaceful heart. Eating tiny portions of food is believed to ensure a tender heart, increases intelligence, encourages humbleness of the soul, reduces temptations, and ensures a gentle temperament (Farid, 1991). This is one of the reasons Muslims fast so they can cleanse themselves of temptation, purifying their souls, which gives the devil little room to move and tempt a person (Farid, 1991).

\section{DIFFERENT STATES OF SOUL}

For Muslims, key methods of dealing with mental health issues are remembering God, seeking forgiveness, patience, gratitude, and praying (Farid, 1991). It is also important to teach mainstream social work students that Muslim believe souls are accountable. For example, the Muslim soul at peace is believed to be one that accepts problems with a sense of surrender, knows it has come from God and accepts it. This type of soul has faith in God's "predestination" and has deep self awareness, taking responsibility for inner peace that is lacking (Farid, p. 54, 1991). The Oft-Blaming Soul is one that moves from positive, and negatives senses of inner peace. One minute the person remembers God and has faith, the next minute the person is forgetful of God (Farid, 1991). The soul directing to sin is an individual that blames God for any type of affliction, and does not give to charity (Farid, 1991). For example, many Muslims will give more to charity if they are experiencing any emotional troubles.

\section{TEACHING STRATEGIES}

One can easily understand why it is so important for mainstream social work students to understand some general beliefs about why Muslims believe they may be suffering emotional troubles. God is certainly seen as key to the helping process, and cannot be ignored in any type of counseling intervention with most Muslim families. The author has used a number of techniques in the classroom to help social work students 
understand their assumptions about Muslims, and what they will need to learn if they want to help Muslim clients effectively. One exercise may be to have students analyze how media affects the way they view Muslims. This can lead to a powerful discussion on stereotypes that can lead to bias in counseling. Students should be taught to be themselves so they appear more personal (Brammer, 2004). It is also important to reframe issues that Muslim clients face in a positive way so clients don't feel so different than a counselor from a different culture (Brammer, 2004). Social work students can also be asked to write personal reflections on what they know about Muslims, and where they learned this from. Each student could read this to the class and classmates could comment on what they think, even challenging some of these beliefs. This can help students realize the hidden messages they have learned about Muslims from families, peers, books etc. Students can also be asked to discuss how spirituality fits or does not fit in their own personal life. They should share how this can impede communication with Muslims who almost always prefer spirituality to guide the general frame of counseling. Students should also be encouraged to do bias checking by having an open dialogue about their concerns about working effectively with Muslim populations. Most importantly, students should also be encouraged to do visits in the Muslim community. They could visit mosques in their community where they can also interview religious heads to ask for advice pertaining to counseling. This allows the mosque to have increased comfort in making referrals to non-Muslim counselors, it also allows for mainstream social workers to build collaborative partners in the Muslims community who could assist in counseling if necessary, and only if the family is agreeable.

\section{CONCLUSION}

Multicultural instructional counseling methods are imperative if we are to ensure that our students of counseling are well prepared to work with diverse families, particularly those from Muslim backgrounds. More studies are needed to assess whether in fact non-Muslim counselor are going to be effective in helping Muslim families. Studies are also needed that address whether Muslim families are reaching out to nonMuslim counselors, and under what circumstances they drop or continue with counseling. To end, more instructors must take an active role to teach social work students that clients are diverse, with varied belief systems of how they prefer their helping experience. Social work students must in turn learn that we live in a multicultural society where people have different beliefs about what can, and will help them. Mainstream social work education must commit itself to addressing unique and diverse forms of counseling techniques.

\section{References}

Al-Krenawi, A. \& Graham, J.R. (1999). Social work and Koranic mental health healers. International Social Work, 42 (1), 53-65.

Brammer, R. (2004). Diversity in counseling. Belmont, CA: Thompson Learning Inc.

Carter, J.D., \& Rashidi, A. (2004). East meets west: Integrating psychotherapy approaches for Muslim Women. Holistic Nursing Practice, May-June, 152-159.

Eliyasee, A.H., \& Pickthall, M.M. (1996). The Holy Qur'aan. Hyderabad, India: Eliasii Family Book Service. 
Farid, A. (1991). The purification of the soul: According to the earliest sources. London: Al-Firdous Ltd.

Khaja, K. (2004). Female circumcision: Life histories of Somali women (Doctoral Dissertation, University of Utah, 2004). Dissertation Abstracts International, 65(2), 584-794.

Pridmore, S. \& Pasha, M.I. (2004). Psychiatry and Islam. Australian Psychiatry,12 (4), 380-385.

Rashid, S. (1999). Islamic influence in America: Struggle, flight and community. Journal of Muslim Minority Affairs, 19 (1), 7-31.

Reizan A., \& Meleis, A. Arab Americans perceptions of and responses to pain. Critical Care Nurse, 1986; 6 (6): 30-37.

Ridley, C.R. (1989). Racism in counseling as an adversive behavior process. In. P.B. Pedersen, J.G. Draguns, W.J. Lonner , \& J.E. Trimble (Eds.), Counseling across cultures ( $2^{\text {nd }}$ ed., pp. 55-78). Honolulu: University of Hawaii Press.

\section{Author's note:}

Address correspondence to: Khadiji Khaja Ph.D., Assistant Professor, Indiana University School of Social Work, 902 West New York Street, ES 4155, Indianapolis, IN 46202. Email: kkhaja@iupui.edu. 